Vol 11, Issue 10, 2018

\title{
ASSOCIATION BETWEEN SERUM URIC ACID AND METABOLIC SYNDROME
}

\author{
THASLIMA NANDHINI JS, SAVITHA BASKER G*, VISHNUPRIYA V
}

Department of Biochemistry, Saveetha Dental College, Saveetha Institute of Medical and Technical Sciences, Saveetha University, Chennai, Tamil Nadu, India. Email: drsavitha80@gmail.com

Received: 10 May 2018, Revised and Accepted: 26 June 2018

ABSTRACT

Objective: Metabolic syndrome is a cluster of disease condition characterized by truncal obesity, hypertriglyceridemia, elevated blood pressure, and insulin resistance. An excessive circulating uric acid (UA) level even within normal range is always comorbid with metabolic syndrome and its components. The aim of the current study was to investigate the association between metabolic syndrome and serum UA level.

Methods: A total of 60 subjects were divided into two groups of healthy (30 individuals) and metabolic syndrome patients (30 individuals) from dental outpatient department of Saveetha Dental College and Hospitals. $5 \mathrm{ml}$ of fasting venous blood was collected in the plain collection tubes and centrifuged, and then serum was separated. Then, the serum was used to analyze the fasting blood glucose, serum triglycerides (TGLs), and serum UA by GOD-POD, enzymatic colorimetric, and uricase method, respectively. A statistical analysis was performed using Student's t-test. p<0.05 was considered to be statistically significant.

Result: Mean body mass index (BMI), fasting blood sugar (FBS), TGL, and UA level of control group were 23.36 $\pm 1.81,84.45 \pm 13.1,110.9 \pm 22.6$, and $3.48 \pm 1.21$ respectively. Mean BMI, FBS, TGL, and UA level of study group were $35.24 \pm 3.04,122.85 \pm 23.3,212.1 \pm 39.6$ and $9.08 \pm 2.63$ respectively. There is a significant difference between these two groups with $\mathrm{p}<0.0001$.

Conclusion: This study showed that those individuals with metabolic syndrome have higher UA level that indicates hyperuricemia which is a significant predictor of metabolic syndrome.

Keywords: Uric acid, Metabolic syndrome, Antioxidants.

(C) 2018 The Authors. Published by Innovare Academic Sciences Pvt Ltd. This is an open access article under the CC BY license (http://creativecommons. org/licenses/by/4. 0/) DOI: http://dx.doi.org/10.22159/ajpcr.2018.v11i10.27233

\section{INTRODUCTION}

Metabolic syndrome is a cluster of risk factors that are characterized as having three or more of the following conditions, i.e., central obesity or high waist circumference ( $>102 \mathrm{~cm}-$ male and $>88 \mathrm{~cm}$ - female), increased triglyceride (TGL) level ( $>150 \mathrm{mg} / \mathrm{dl})$, elevated blood pressure ( $>130 / 90 \mathrm{~mm}$ of $\mathrm{Hg})$, impaired fasting glucose $(>100 \mathrm{mg} / \mathrm{dl})$, and decreased high-density lipoprotein cholesterol $(>35 \mathrm{mg} / \mathrm{dl}$ for male and $0.50 \mathrm{mg} / \mathrm{dl}$ for female) [1-5]. The presence of metabolic syndrome is strongly associated with the development of diabetes, hypertension, cardiovascular disease, stroke, and chronic kidney disease [6].

Uric acid (UA) is synthesized mainly in the liver, intestines, and other tissues such as muscles, kidneys, and vascular endothelium as the end product of an exogenous pool of purines, derived largely from animal proteins. The live and dying cells degrade their nucleic acids (adenine and guanine) into UA $[1,7]$. The main physiological function of UA is a strong reactive oxygen species and peroxynitrite scavenger and antioxidant [7-10]. UA is a powerful scavenger of free radicals and provides approximately $60 \%$ of free-radical scavenging capacity in the blood. Increased circulating level of UA indicates an adaptive response to protect against the excessive free radicals and oxidative stress $[9,11,12]$.

Hence, the aim of the current study is to assess the level of UA in metabolic syndrome individuals.

\section{METHODS}

Patients were selected from those attending the outpatient department of Saveetha Dental College and Hospitals and divided into two groups as follows:
Group I - Normal healthy individuals - 30 individuals Group II - Patients with metabolic syndrome - 30 individuals.

\section{Inclusion criteria}

The following criteria were included in the study:

- Individuals with the age group of 35-55 years

- Individuals with type 2 diabetes mellitus (fasting blood sugar [FBS] $\geq 100 \mathrm{mg} / \mathrm{dl}$ )

- Individual with normal body mass index (BMI) (18.9-24.9) and obese BMI $(\geq 30)$

- $\quad$ Serum TGL levels $>150 \mathrm{mg} / \mathrm{dl}$.

\section{Exclusion criteria}

The following criteria were excluded from the study:

- Individuals with other systemic illness such as cardiovascular disease, renal failure, stroke, and endocrine illness

- Individuals with acute illness like fever

- Immunocompromised individuals.

\section{Sample collection}

Informed consent was obtained from the patient before sample collection. $5 \mathrm{ml}$ of fasting venous blood was collected and distributed in plain collection tubes and centrifuged in $3000 \mathrm{rpm}$ for serum. Then serum was separated, and then, it is analyzed for FBS by GOD-POD method, serum TGL by colorimetric enzymatic method, serum UA by uricase/peroxidase method, and ERBA CHEM 5 plus analyzer.

\section{RESULTS}

All the data were analyzed using SPSS software. Student's t-test analysis was performed to find significant differences between the two groups. All the tests were considered statistically significant at $\mathrm{p}<0.05$ level. 
Table 1: Mean, SD, and $P$ values of BMI, FBS, TGL, and UA level in two groups

\begin{tabular}{llll}
\hline Parameters & Control & Metabolic syndrome & p value \\
\hline BMI & $23.36 \pm 1.81$ & $35.94 \pm 3.04$ & $<0.001$ \\
FBS (mg/dl) & $84.45 \pm 13.1$ & $122.85 \pm 23.3$ & $<0.000$ \\
TGL (mg/dl) & $110.9 \pm 22.6$ & $212.1 \pm 39.6$ & $<0.000$ \\
UA (mg/dl) & $3.48 \pm 1.21$ & $9.08 \pm 2.63$ & $<0.001$ \\
\hline
\end{tabular}

SD: Standard deviation, BMI: Body mass index, FBS: Fasting blood sugar, TGL: Triglyceride, UA: Uric acid

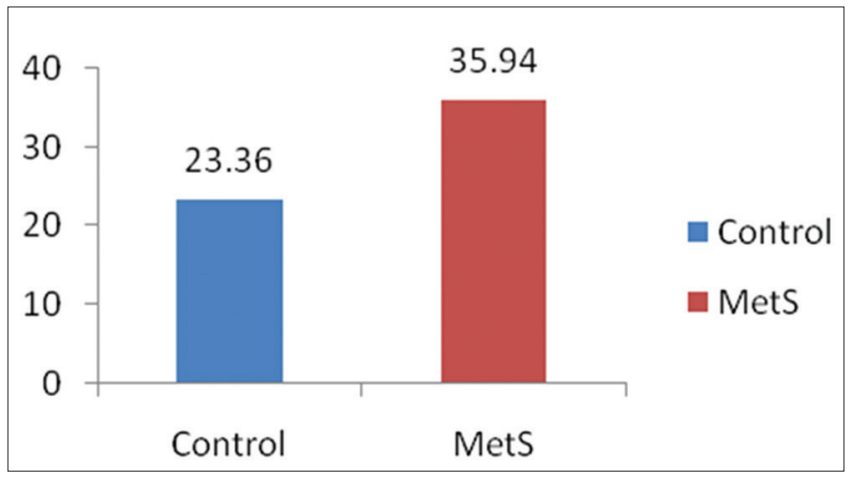

Fig. 1: Mean body mass index levels in two groups

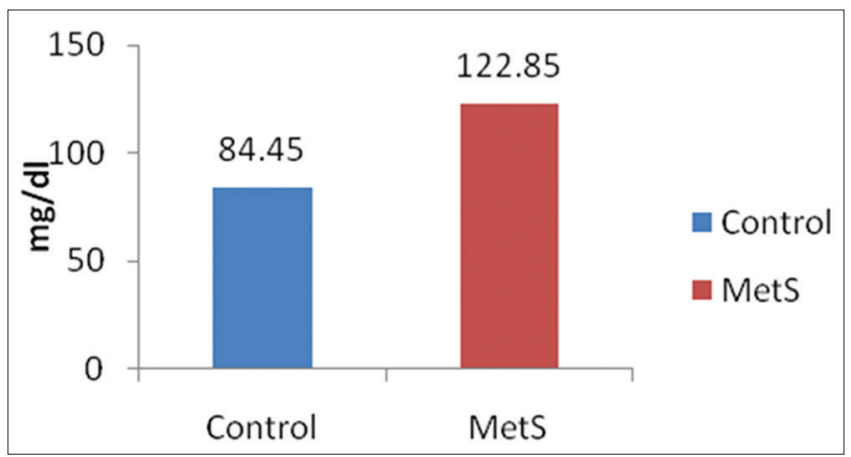

Fig. 2: Mean fasting blood sugar levels in two groups

\section{DISCUSSION}

Mean BMI level in the control and study groups was $23.36 \pm 1.81$ and 35.94 \pm 3.04 , respectively, (Table 1 and Fig. 1). Mean FBS level in control and study groups was $84.45 \pm 13.1$ and $122.85 \pm 23.3$, respectively (Table 1 and Fig. 2). Mean TGL level in control and study groups was $110.9 \pm 22.6$ and 212.1 \pm 39.6 , respectively (Table 1 and Fig. 3). Mean UA level in control and study groups was $3.48 \pm 1.21$ and $9.08 \pm 2.63$, respectively (Table 1 and Fig. 4).

The BMI, FBS, and TGL levels in metabolic syndrome individuals were significantly high when compared to the healthy individuals, which indicate proper selection of study groups. The UA level was significantly high in metabolic syndrome individuals when compared to the healthy individuals $(\mathrm{p}=0.0001)$.

Our results suggest that UA level was increased in metabolic syndrome individuals. Metabolic syndrome is a cluster of many disease conditions such as diabetes mellitus, hypertension, dyslipidemia, and central adiposity. In all the components of metabolic syndrome, free radical production is increased which leads to oxidative stress and damage of other cells causing progression of the disease condition $[13,14]$. These processes are prevented by our body defense mechanism called antioxidants. There are enzymatic and non-enzymatic antioxidants. In non-enzymatic antioxidant, UA is a metabolic antioxidant which

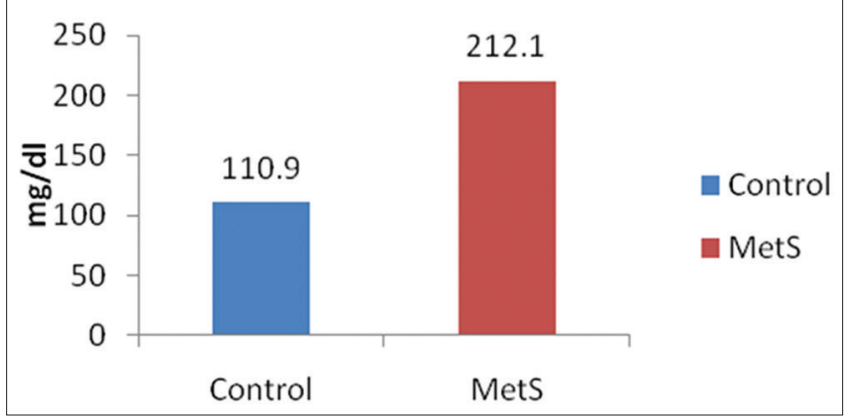

Fig. 3: Mean triglycerides levels in two groups

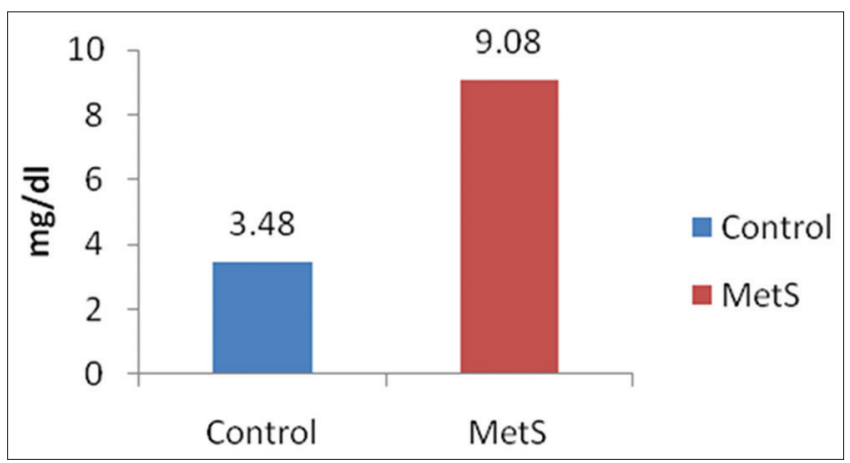

Fig. 4: Mean uric acid levels in two groups

is the end product of purine metabolism. Hence, it inhibits the action of free radicals such as peroxyl radicals and peroxynitrite, and thus, it protects the cell membrane and DNA and reduces the oxidative stress [15]. The major pathogenesis behind the metabolic syndrome is insulin resistance or hyperinsulinemia [16]. Many studies suggest that increased UA level is due to increased absorption of the UA from the proximal convoluted tubules secondary to hyperinsulinemia $[17,18]$. All these factors suggested that UA level was increased in metabolic syndrome individuals.

\section{CONCLUSION}

This study showed that those individuals with metabolic syndrome have higher UA level that indicates hyperuricemia which is a significant predictor of metabolic syndrome. The increased UA levels reduce the oxidative stress and thus protect the cell membrane and DNA.

\section{AUTHORS' CONTRIBUTIONS}

Concept and study design were done by Dr. G.Savitha and Dr. V.Vishnupriya. Data acquisition was done by Miss. J.S. Thaslima Nandhini. Data interpretation, statistical analysis, manuscript drafting, and review were done by all three authors. All authors took part in the conduction of the study.

\section{CONFLICTS OF INTEREST}

The authors of this article declare no conflict of interest in this study.

\section{FINANCIAL SUPPORT AND SPONSORSHIP}

Nil.

\section{REFERENCES}

1. Nejatinamini S, Ataie-Jafari A, Qorbani M, Nikoohemat S, Kelishadi R, Asayesh $\mathrm{H}$, et al. Association between serum uric acid level and metabolic syndrome components. J Diabetes Metab Disord 2015;14:70.

2. Guru EP, Savitha G. Prevalence of coronary atherosclerotic heart disease in metabolic syndrome patients. J Pharm Sci Res 2015;7 Suppl 9:724-6.

3. Mounoka S, Savitha G. Association of periodontal diseases and 
metabolic syndrome. Res J Pharm Tech 2015;8 Suppl 8:994-6.

4. Nerkar D, Mukherjee A, Mehta BK, Banerjee S. Metabolic syndrome associated complications. Int J Pharm Pharm Sci 2015;7 Suppl 7:22-5.

5. Yuan H, Yu C, Li X, Sun L, Zhu X, Zhao C, et al. Serum uric acid levels and risk of metabolic syndrome: A Dose-response meta-analysis of prospective studies. J Clin Endocrinol Metab 2015;100:4198-207.

6. Cirillo P, Sato W, Reungjui S, Heinig M, Gersch M, Sautin Y, et al. Uric acid, the metabolic syndrome, and renal disease. J Am Soc Nephrol 2006;17:S165-8

7. Ridi RE, Tallima H. Physiological functions and pathological potential of uric acid: A review. J Adv Res 2017;8 Suppl 5:487-93.

8. Beckar BF. Towards the physiological function of uric acid. Free Radic Biol Med 1993;14 Suppl 6:615-631.

9. Glantzounik GK, Tsimoyiannis EC, Kappas AM, Galaris DA. Uric acid and oxidative stress. Curr Pharm Des 2005;11 Suppl 32:4145-51.

10. Alexander SO, Thorens B. Uric acid transport and disease. J Clin Invest 2010;120 Suppl 6:1791-9.

11. Fabbrini E, Serafini M, Colic Baric I, Hazen SL, Klein S. Effect of plasma uric acid on antioxidant capacity, oxidative stress, and insulin sensitivity in obese subjects. Diabetes 2014;63:976-81.

12. Ames BN, Cathcart R, Schwiers E, Hochstein P. Uric acid provides an antioxidant defense in humans against oxidant- and radical-caused aging and cancer: A hypothesis. Proc Natl Acad Sci U S A 1981;78:6858-62.

13. Kwak HK, Yoon S. Relation of serum total antioxidant status with metabolic risk factors in Korean adults. Nutr Res Pract 2007;1:335-40.

14. Najarzadeh A, Mozaffari-Khosravi H, Mahdavi M, Fallahzadeh H, Zavar-Reza J, Shahmoradi H. Antioxidant status in patients with metabolic syndrome as measured by the stable free radical diphenylpicrylhydrazyl Assay. Iran J Diabetes Obesity 2012;40:161-6.

15. Silva HA, Carraro JC, Bressan J, Hermsdorff HH. Relation between uric acid and metabolic syndrome. Einstein 2015;13 Suppl 2:202-8

16. Usama AA, El Din S, Salem MM, Abdulazim DO. Uricacid in the pathogenesis of metabolic, renal and cardiovascular diseases: A review. J Adv Res 2017;8 Suppl 5:537-48.

17. Chen LY, Zhu WH, Chen ZW, Dai HL, Ren JJ, Chen JH, et al. Relationship between hyperuricemia and metabolic syndrome. J Zhejiang Univ Sci B 2007;8:593-8.

18. Lee D, Oh WJ, Yi MK, Han SW, Yun JW, Han SH. The relevance of hyperuricemia and metabolic syndrome and the effect of blood Lead level on uricacid concentration in steelmaking workers. Ann Occup Environ Med 2013;25:27. 